\title{
Design of Digital Secured box using IoT with Raspberry Pi
}

\author{
R. Ramprakash, K. Subbareddy, P. Praveen
}

\begin{abstract}
With expansion of crimes in public, Safety and security have turned into an essential worry for all. It is prudent to have the money, adornments and different assets under safe authority since criminals nowadays are very technically knowledgeable and they have a great deal of current gear's with them. Thieves are currently outfitted with instruments and they can demolish the greater part of the traditional wellbeing storage frameworks. Advanced Secured Box is a verified box where we can put in the requests into the container securely and get to it with the nonattendance of the client. At the point when the request came to the conveyance address, conveyance individual calls the client and requests the secret word to open the Digital Secured Box. This crate comprises of two layers where first layer is utilized to put the item into the container and the second layer is utilized to verify the online items. At the point when the conveyance individual calls the client, there produces an arbitrary OTP without fail. OTP is given to the conveyance kid that is composed through a keypad which is set on the case.
\end{abstract}

Keywords: IOT, OTP.

\section{INTRODUCTION}

\subsection{IoT(Internet of Things)}

The IOT is the combination of gadgets, house equipment's like washing machine etc. moreover distinctive things introduced with programming like sensors attenuators, additionally accessibility that empowers these items ought to cohort additionally trade majority of the info. Each relic may be especially unmistakable through its embedded registering schema yet might between fill in inside the current web establishment. Those IoT empowers things with be distinguished alternately regulated remotely accessible In existing framework framework, making gateways to a greater amount direct blend of the physical globe under pc based frameworks, What's more bringing something like progressed effectiveness, precision What's more fiscal advantage Despite reduced human intervention. To this end At IoT can be expanded for sensors as well as attenuators, the progress an example of the All the wider class from claiming sophisticated physical frameworks, which also includes developments, fascinating networks, wise homes, insightful transportation and magnificent urban communities."

Revised Manuscript Received on February 05, 2020.

* Correspondence Author

R. Ramprakash, Assistant Professor,, Department of ECE AGI, Hyderabad.

K. Subbareddy, Assistant Professor,, Department of ECE AGI, Hyderabad

P. Praveen, Assistant Professor,, Department of ECE AGI, Hyderabad

(C) The Authors. Published by Blue Eyes Intelligence Engineering and Sciences Publication (BEIESP). This is an open access article under the CC BY-NC-ND license (http://creativecommons.org/licenses/by-nc-nd/4.0/)
Things," in the IoT are gadgets like camera temperature sensor any biological sensors to sense or capture any visual parameter for diagnosing. Lawful researchers recommend with respect to "things" as an "inseparable blend of equipment, programming, information and administration". These gadgets acquire valuable data With the help of various current developments, the data is then streamed between distinct gadgets.

\subsubsection{ARCHITECTURE}

IOT comprises of many layers of advances supporting IOT. It serves to analyse the advances identify with one another and to convey the adaptability, measured quality and arrangement of IOT organizations in various situations. Design of IOT contains these layers.

\subsubsection{APPLICATION LAYER:}

The application layer does conveying application suiting explicit administrations to the client. It characterizes many applications in which the IOT can be sent. It is the most minimal deliberation layer, with sensors we are making advanced sensory system. It is consolidated to quantify physical amounts and it likewise interconnects the physical and advanced world.

The IoT application handles "smart" conditions in areas, for example, house,Transportation,hospital, Building, City, Retail, Agriculture, Factory, Emergency, User connection, Culture and the travel industry, Environment and Energy.

\subsubsection{GATEWAY AND NETWORK LAYER}

Big data is gathered and to process and handle this date from sensors etc network layer must be strong .

\subsubsection{SENSOR LAYER}

Sensors are necessary to communicate the real world data to pi sensors like temperature etc

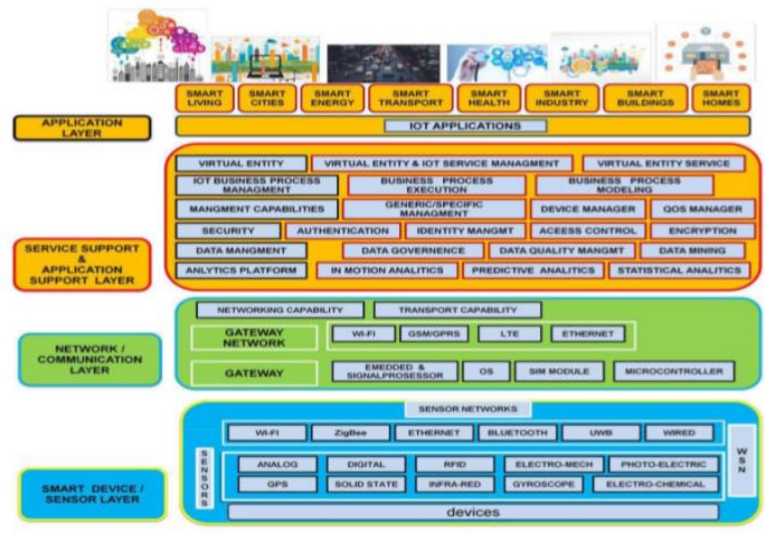

Fig 1 IOT architecture 


\section{Design of Digital Secured box using IoT with Raspberry Pi}

\subsection{HOW DOES IT WORK}

Gadgets communicate with internet calling IOT,every sensor data is sent to cloud and accessed and computed how to control the process of hard ware flow.

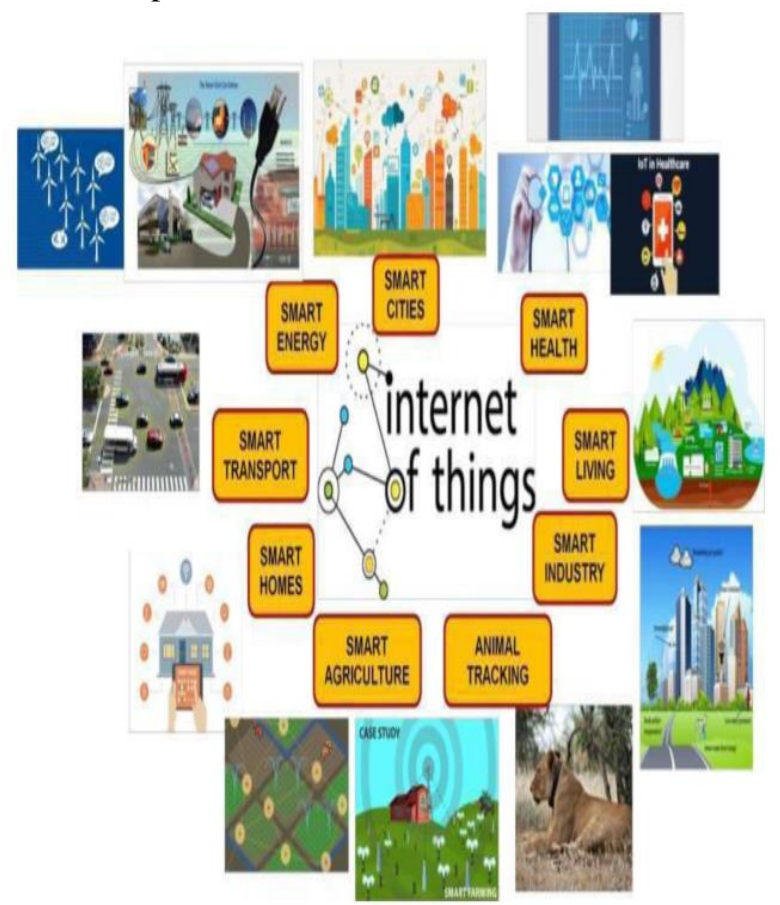

Fig 2. IOT Applications

\subsection{OBJECTIVE}

The digital secure box is safe alternate to secure uour delivery package . Our main focus is on the home deliveries. To keep the delivery product to be safe and secure even in the absence of the house holders using locking system as Digital Secured Box at every house. Digital secured box acts as the locker system in which the delivery products can be placed in it and can have an access through the phone OPT message with internet connectivity.

\subsection{METHODOLOGY}

\subsubsection{EXISTING SYSTEM:}

In present scenario, we don't have proper system for Home Delivery.The visit of delivery person to the customer increases until he/she is available. If the customer is not available at delivery address, then the delivery person has to return the product to its actual address (Ex: bluedart couriers). There may be a chance of our product going into hands of unknown and untruth person.And the product has to be unplaced if the customer is out of station for more than a week.the person has to be present at the time of delivery if delivery is placed near door chances are high that the package may be stolen. It leads to enormous increase in the cost of travel and wastage of time for delivery person. In smart growing cities this scenario is not preferable to the customers or the delivery persons in lack of time.This system is only allowed when the customer is at home at the time of delivery. So that the product is given to the customer through a delivery person. Unless and until the customer is not at home, there is no guarantee that the product is safe and reached to the customer or not.

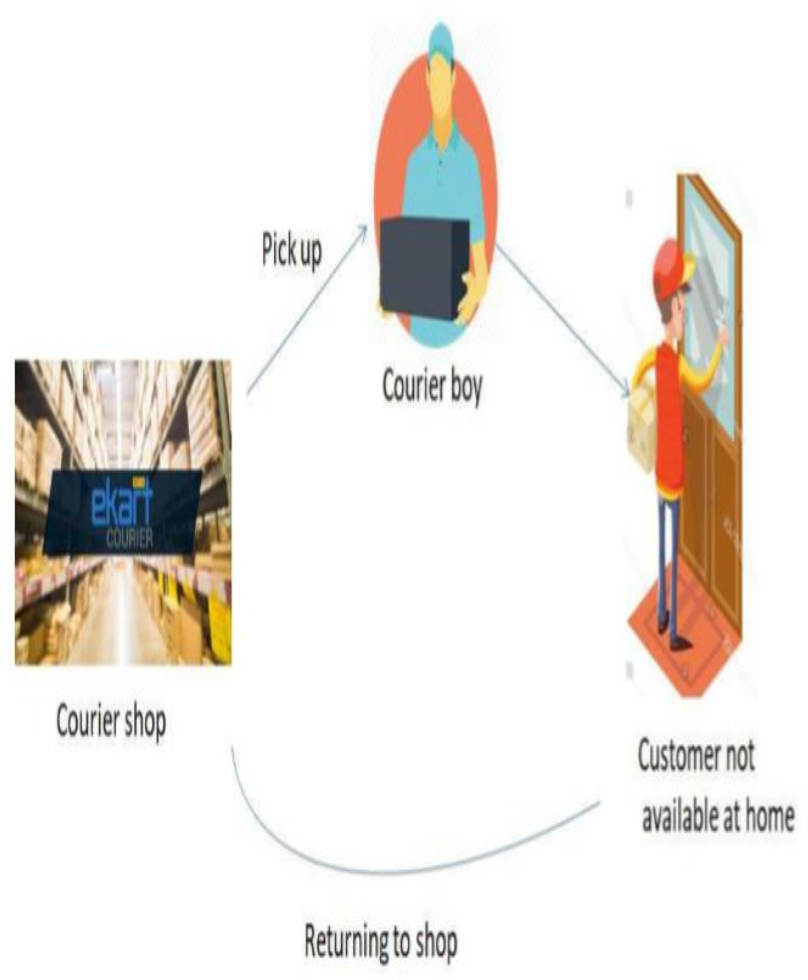

Fig 3. Existing System

\subsubsection{PROPOSED SYSTEM}

In order to overcome the limitations in present system, we came up with a new idea of having "Digital secured box" at every house. Digital Secured Box is a secured box where we can place the orders into the box safely and access it with the absence of the customer.When the order reached to the delivery address, delivery person calls the customer and asks for the password to open the Digital Secured Box.This box consists of two layers where first layer is used to place the product into the box and the second layer is used to secure the online products. When the delivery person calls the customer, there generates a random OTP every time. OTP is given to the delivery boy that is typed through a keypad which is placed on the box. We can see a LCD display to enter the password. If the entered password is wrong it indicates us to type the correct OTP which has given to the delivery person. Then the door opens automatically so the delivery person can place the product into the box then the door closes automatically within 15-20 Secs. After sensing that the product is placed in the first layer through Ultrasonic sensor, the door will open to the second layer and the product is secured in the bottom of the layer and the door for the second layer closes which can't be seen. In this manner the products are secured with in the box. Customer can order more than one product per day. More than one delivery person can access the Digital Secured box more than once per a day. Finally that secured products can be taken by the customer from the back door using a door locking system. 


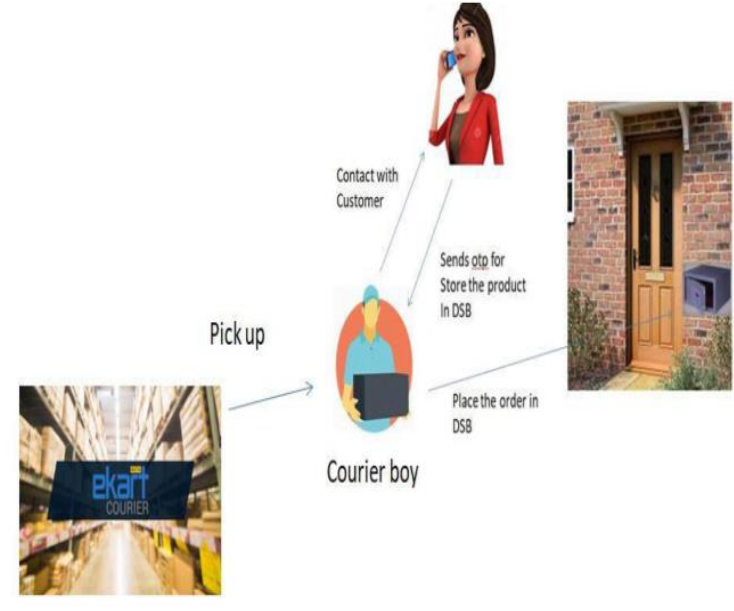

Courier shop

Fig 4. Proposed System

\section{DESIGN ASPECTS}

The system can be represented using algorithms and algorithms are designed using flowcharts.

Here we come up with a scenario that when we place a order in any shopping site, we come across a situation that the customer may not be at home at the time of delivery and the product is taken back to the shopping sites. Based on this situation we came up with a Digital Secured Box where we can place the orders into the box safely and access it with the absence of the customer.

When the order reached to the delivery address, delivery person calls the customer and asks for the password to open the Digital Secured Box. This box consists of two layers where first layer is used to place the product into the box and the second layer is used to secure the online products. When the delivery person calls the customer, there generates a random OPT every time.

OTP is given to the delivery boy that is typed through a keypad which is placed on the box .We can see a LCD display to enter password. If entered pass is wrong it indicates us to type the correct OPT which has given. Then the door opens automatically so the delivery person can place the product into the box then the door closed automatically within 15-20 Secs. After sensing that the product is placed in the first layer through Ultrasonic sensor, the door will open to the second layer and the product is secured in the bottom of the layer and the door for the second layer will be closed. In this manner the products are secured with in the box. So the customer can order more than one product per day and more than one delivery person can access the Digital Secured box more than once per a day. Finally that secured products can be taken by the customer from the back door using a door locking system.

\subsection{BLOCK DIAGRAM}

\subsection{FLOW CHART}

Fig 6. Flow chart

Fig 5. Block diagram
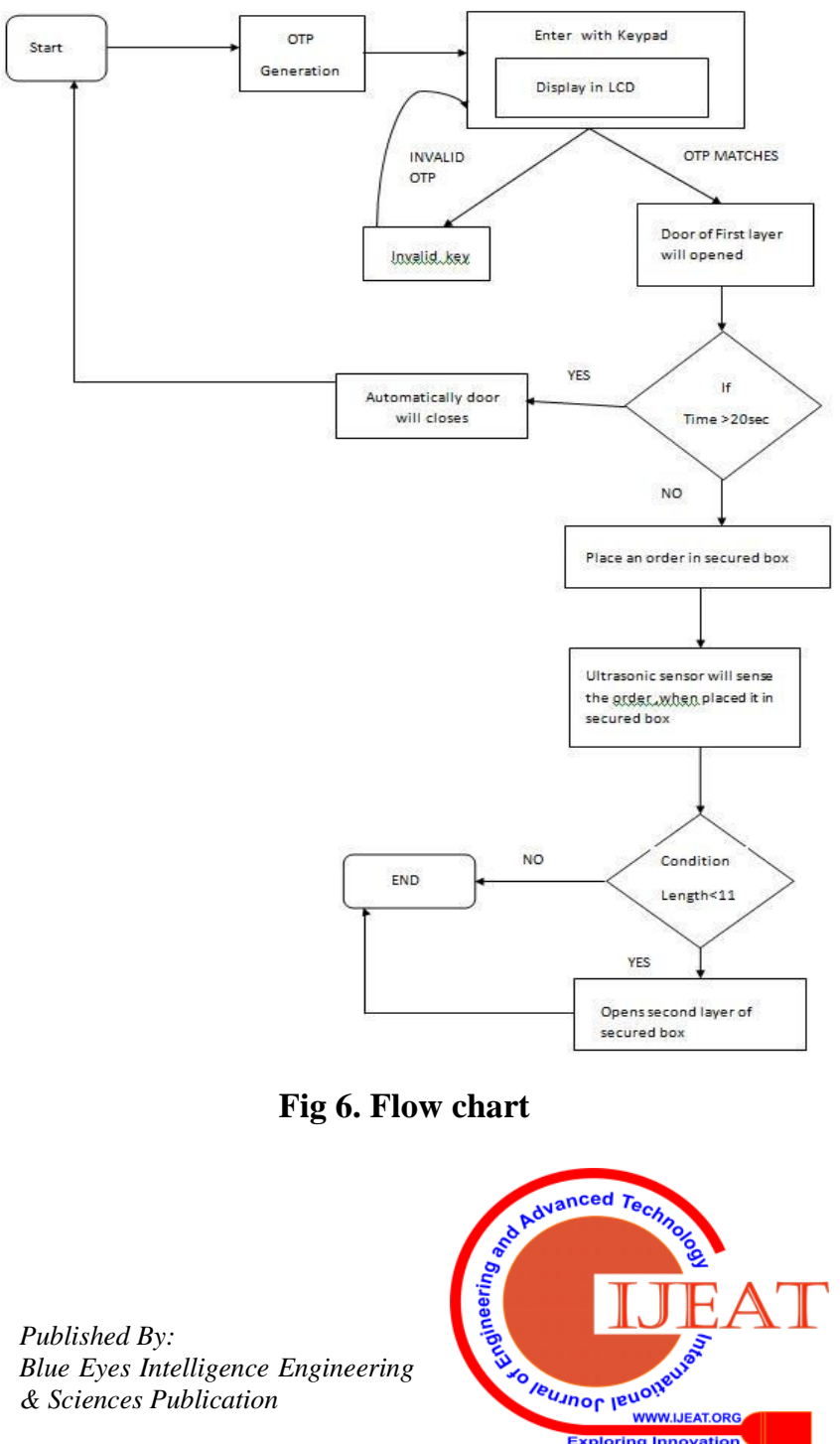


\section{Design of Digital Secured box using IoT with Raspberry Pi}

The use of raspberry pi as pc alternative can perform the task better and having comp ability to connect with more hardware components like ardino.the programing used is python .

\section{PROJECT TEST SETUP AND TEST RESULT}

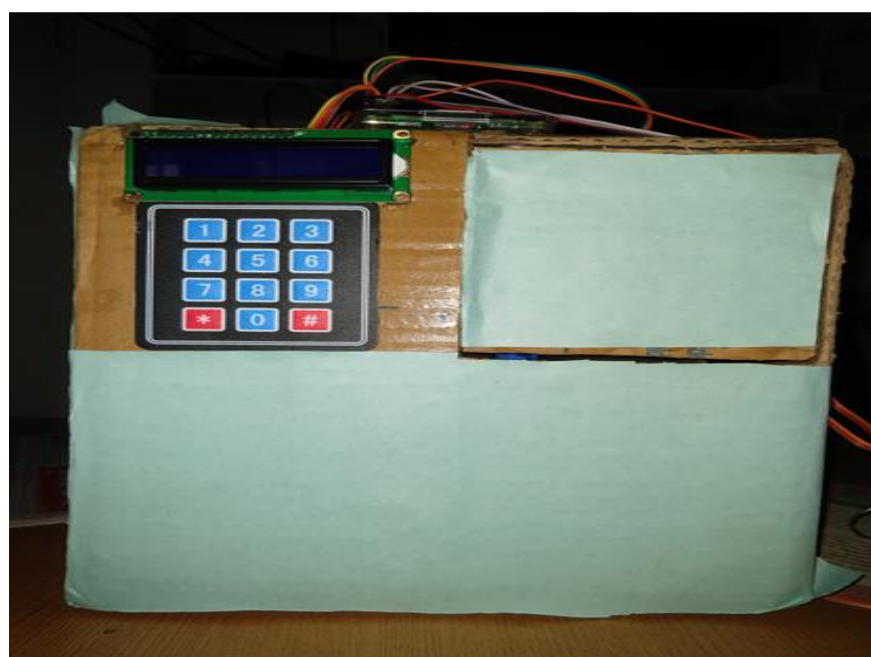

Fig 7. Front View

- $\quad$ Above figure shows the front view of the Digital Secured Box with all the connections.

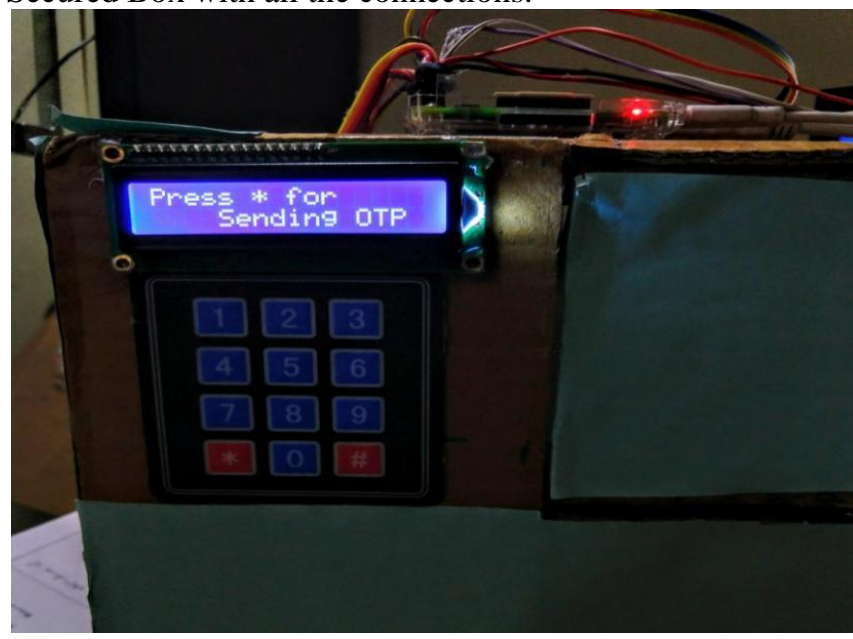

Fig 8. Sending OTP

- $\quad$ By pressing star otp will be sent to customer or owner

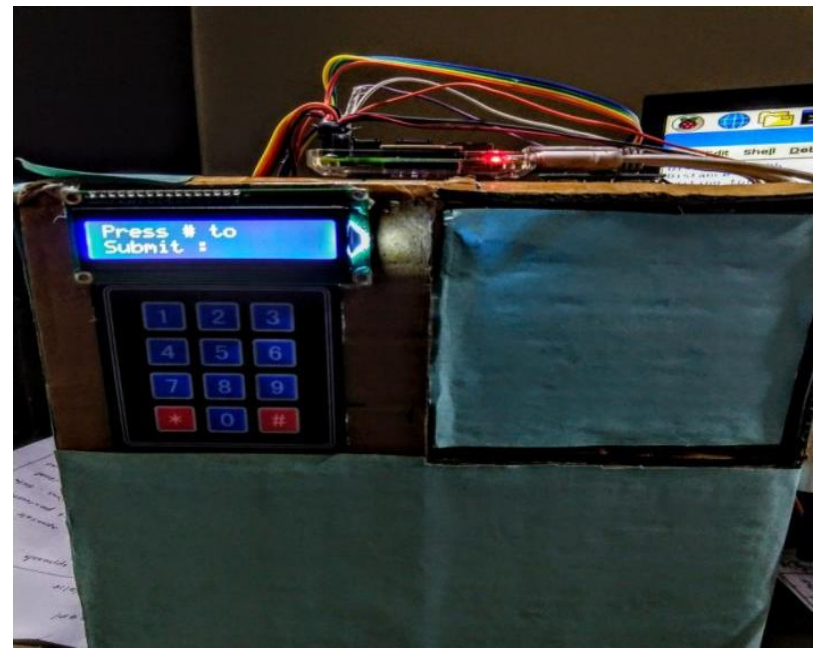

Fig 9.Submit OTP

- $\quad$ After entering OTP press \# to submit it.

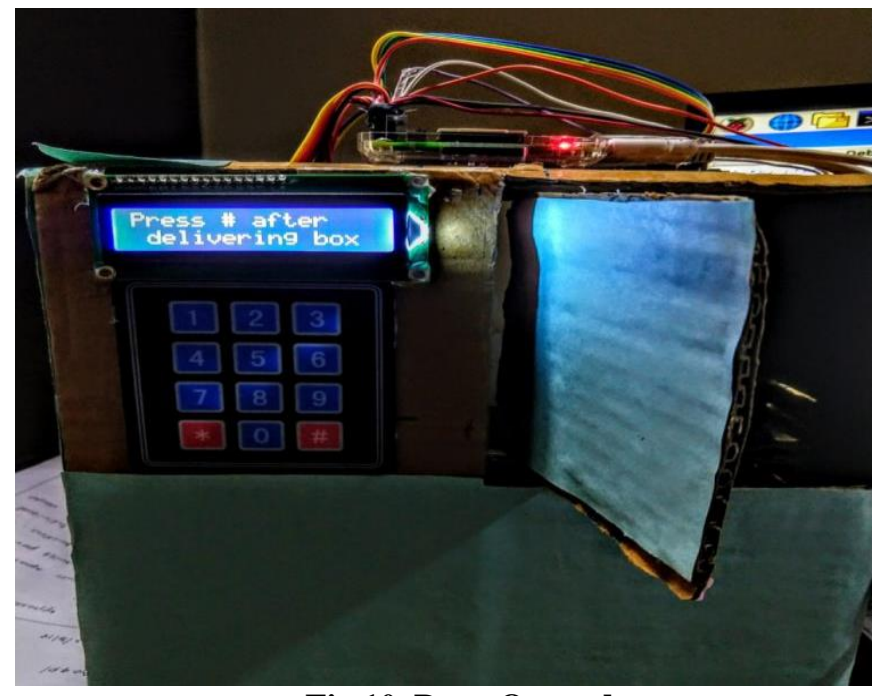

Fig 10. Door Opened

After submission of OTP the Door will Be Opened.After keeping the delivery inside the box press \# to close the door.

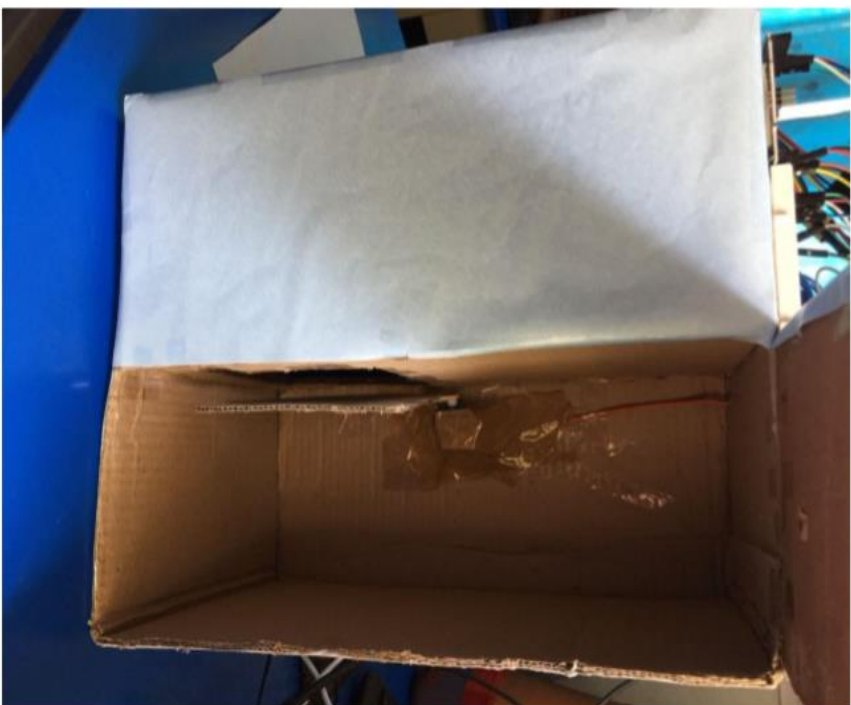

Fig 11. Back View

Back view of Digital Secured Box is shown and inside we have an second door, it opens when the product is placed in the box. The product is secured in the space showed in the figure.

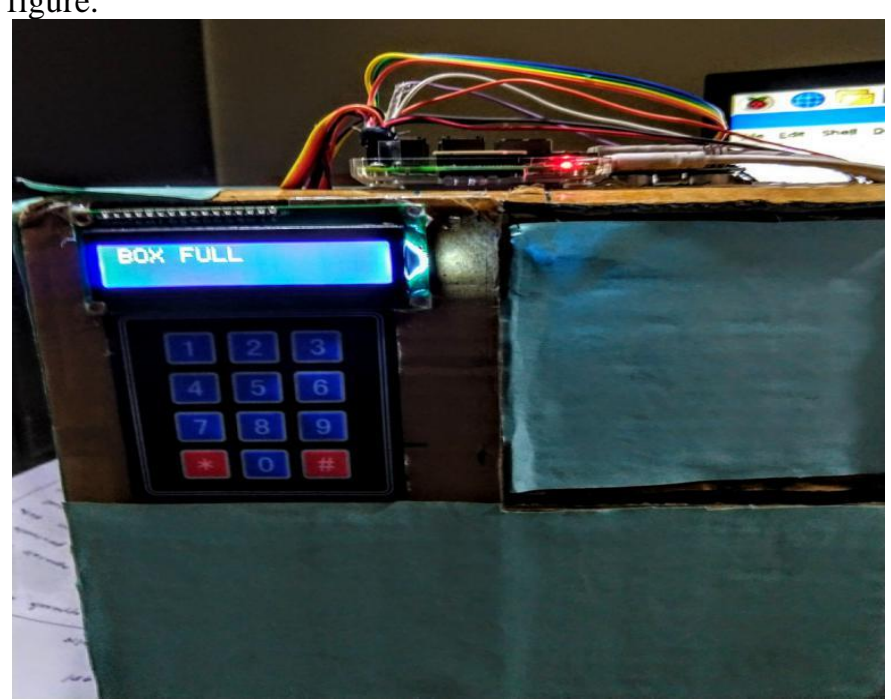

Fig 12. Box Ful

Published By:

Blue Eyes Intelligence Engineering \& Sciences Publication

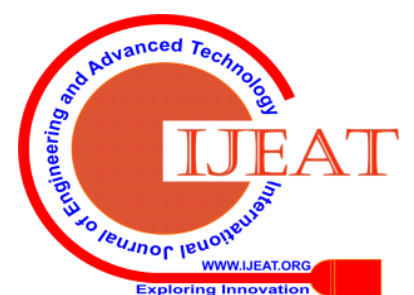


If the box is filled with delivery products it displays box is full

\section{TEST CASES}

\begin{tabular}{|c|c|c|c|c|}
\hline Test case No & Test case name & Description & Output & Status \\
\hline 01 & $\begin{array}{l}\text { Opening of outer } \\
\text { door }\end{array}$ & $\begin{array}{l}\text { Check whether outer } \\
\text { door opens when key } \\
\text { OTP is entered }\end{array}$ & $\begin{array}{l}\text { Outer door opens } \\
\text { when entered OTP. }\end{array}$ & Pass \\
\hline 02 & $\begin{array}{l}\text { Not Opening of outer } \\
\text { door }\end{array}$ & $\begin{array}{l}\text { When OTPentered } \\
\text { incorrect }\end{array}$ & Door does not open & Pass \\
\hline 03 & OTP & $\begin{array}{c}\text { Check whether the OTP } \\
\text { is sent tothe mobile of } \\
\text { delivery boy. }\end{array}$ & $\begin{array}{l}\text { The OIP is correctly } \\
\text { sent to the mobile of } \\
\text { deliveryboy on } \\
\text { ariving. }\end{array}$ & Pass \\
\hline 04 & $\begin{array}{c}\text { Opening of Inner } \\
\text { door when placed } \\
\text { object }\end{array}$ & $\begin{array}{l}\text { Check whether Inner } \\
\text { door opens when the } \\
\text { object is placed. }\end{array}$ & $\begin{array}{l}\text { Inner door opens } \\
\text { after detecting the } \\
\text { presence of object. }\end{array}$ & Pass \\
\hline 05 & $\begin{array}{c}\text { Not opening of Inner } \\
\text { door when object is } \\
\text { not placed }\end{array}$ & $\begin{array}{l}\text { Check whether Inner } \\
\text { door is not opened when } \\
\text { the object is not placed in } \\
\text { the first compartment. }\end{array}$ & $\begin{array}{l}\text { Inner door does not } \\
\text { open when the object } \\
\text { is not placed inside. }\end{array}$ & Pass \\
\hline
\end{tabular}

\subsection{ADVANTAGES}

- Usage of Digital Secured Box at every house ensures safe and secured delivery.

- $\quad$ Highly profitable for Home deliveries.

- $\quad$ Online shopping products can be delivered with the absence of the customer.

- $\quad$ Access to the Digital secured box can be made through an OPT which is send to the delivery person which acts a password.

- $\quad$ Efficiently used more than once a day.

- $\quad$ More than one delivery product can be stored in the box as per the requirement.

- $\quad$ Presence of the product in the box can also be noticed through a sensor present in it.

\subsection{LIMITATIONS}

- Delivery of correct product is not detected when replaced with incorrect product.

- $\quad$ Size of the box is not specified, it depends on the size of the delivery product.

\section{CONCLUSION AND FUTURE SCOPE}

Due to the recent trends in various methods of security for delivery products, this idea focus on all security issues for delivery products. It adds security to the delivery which indirectly increases sales and trust of customer.

Digital Secured box provides high security for the product with locking system. Digital secured box is used even in the absence of customer. It is very efficient to both for the delivery person and also the customer. As safety is concerned digital secure box are future for online delivery. Based on the size of delivery products, the size of the box can be maintained.

\section{REFERENCES}

1. Kafle, V. P., Fukushima, Y., \& Harai, H. (2015, April). ID-based communication for realizing IoT and M2M in future heterogeneous mobile networks. In Recent Advances in Internet of Things (RIoT), 2015 International Conference on (pp. 1-6). IEEE.

2. Dash, S. K., Mohapatra, S., \& Pattnaik, P. K. (2010). A survey on applications of wireless sensor network using cloud computing.
International Journal of Computer science \& Engineering Technologies (EISSN: 2044-6004), 1(4), 50-55. 